\title{
Maillard Reaction Products and Their Relation to Complications in Insulin-dependent Diabetes Mellitus
}

\author{
David R. McCance, * Daniel G. Dyer, ${ }^{\ddagger}$ John A. Dunn, ${ }^{*}$ Karen E. Bailie, Suzanne R. Thorpe, ${ }^{\star}$ \\ John W. Baynes, ${ }^{* 1}$ and Timothy J. Lyons *s" \\ ${ }^{*}$ Sir George E. Clark Metabolic Unit, Royal Victoria Hospital, Belfast BT12 6BA, Northern Ireland, United Kingdom; ${ }^{\ddagger}$ Department of \\ Chemistry and Biochemistry, and "School of Medicine, University of South Carolina, Columbia, South Carolina 29210; ${ }^{\S}$ Department \\ of Medicine, Altnagelvin Hospital, Londonderry BT47 1JB, Northern Ireland, United Kingdom; "Division of Endocrinology, Diabetes \\ and Metabolism, Medical University of South Carolina, Charleston, South Carolina 29425, and Ralph H. Johnson Department of \\ Veterans Affairs Medical Center, Charleston, South Carolina 29401
}

\begin{abstract}
Glycation, oxidation, and browning of proteins have all been implicated in the development of diabetic complications. We measured the initial Amadori adduct, fructoselysine (FL); two Maillard products, $N^{\epsilon}$-(carboxymethyl) lysine (CML) and pentosidine; and fluorescence (excitation $=328 \mathrm{~nm}$, emission $=378 \mathrm{~nm}$ ) in skin collagen from 39 type 1 diabetic patients (aged 41.5 $\pm 15.3[17-73] \mathrm{yr}$; duration of diabetes $17.9 \pm 11.5$ [0-46] yr, [mean $\pm \mathrm{SD}$, range]). The measurements were related to the presence of background $(n=9)$ or proliferative ( $n$ $=16$ ) retinopathy; early nephropathy (24-h albumin excretion rate $\left[\mathrm{AER}^{24}\right] \geq 20 \mu \mathrm{g} / \mathrm{min} ; n=9$ ); and limited joint mobility ( LJM; $n=20$ ). FL, CML, pentosidine, and fluorescence increased progressively across diabetic retinopathy $(P<0.05, P$ $<0.001, P<0.05, P<0.01$, respectively). FL, CML, pentosidine, and fluorescence were also elevated in patients with early nephropathy $(P<0.05, P<0.001, P<0.01, P<0.01$, respectively). There was no association with LJM. Controlling for age, sex, and duration of diabetes using logistic regression, FL and CML were independently associated with retinopathy (FL odds ratio $(\mathrm{OR})=1.06,95 \%$ confidence interval $(\mathrm{CI})=1.01-$ 1.12, $P<0.05 ;$ CML OR $=6.77,95 \%$ CI $=1.33-34.56, P$ $<0.05$ ) and with early nephropathy (FL OR $=1.05,95 \%$ CI $=1.01-1.10, P<0.05 ;$ CML OR $=13.44,95 \% \mathrm{CI}=2.00$ 93.30, $P<0.01)$. The associations between fluorescence and retinopathy and between pentosidine and nephropathy approached significance $(P=0.05)$. These data show that FL and Maillard products in skin correlate with functional abnormalities in other tissues and suggest that protein glycation and oxidation (glycoxidation) may be implicated in the development of diabetic retinopathy and early nephropathy. (J. Clin. Invest. 1993. 91:2470-2478.) Key words: collagen - complications of diabetes • glycation • oxidation • nonenzymatic browning
\end{abstract}

Dr. McCance's current address is National Institute of Diabetes and Digestive and Kidney Diseases, 1550 East Indian School Road, Phoenix, AZ 85014.

Address reprint requests to Dr. Lyons, Division of Endocrinology, Diabetes and Metabolism, Medical University of South Carolina, 171 Ashley Avenue, Charleston, SC 29425.

Received for publication 11 May 1992 and in revised form 2 December 1992.

J. Clin. Invest.

(c) The American Society for Clinical Investigation, Inc.

0021-9738/93/06/2470/09 \$2.00

Volume 91, June 1993, 2470-2478

\section{Introduction}

A central issue in current diabetes research concerns the pathogenesis of diabetic complications (1-7), and in particular, the role of hyperglycemia in their development (8). Despite the problems involved in obtaining a satisfactory index of longterm blood glucose control, many clinical and epidemiological studies have supported an association between glycemic control and complications (9-17). Glycation (nonenzymatic glycosylation), a ubiquitous chemical modification of proteins exposed to reducing sugars, provides the basis for an attractive hypothesis to explain this association. This hypothesis states that the biochemical, structural and functional consequences of increased protein glycation contribute to the development of complications.

Collagen is a long-lived protein found throughout the body. With advancing age, it undergoes marked physicochemical changes, including decreased solubility, elasticity, and sensitivity to protease digestion (18), and increased thermal stability $(19,20)$. These changes are accelerated in diabetic patients (21), whose collagen contains significantly increased quantities of the initial product of glycation, fructoselysine $(F L)^{1}$ (22). However, there is little evidence to date that FL is directly implicated in the altered properties of collagen. The FL content of skin collagen increases only slightly with age in nondiabetic individuals $(22,23)$, and although elevated in diabetes, it is unrelated to age or duration of diabetes (22). In existing studies, collagen FL has not been associated with the presence or severity of diabetic complications $(24,25)$, and even in patients with long-standing diabetes, its concentration in collagen falls promptly with improved glycemic control (26). In vitro, short-term glycation of collagen does not increase its resistance to enzymatic digestion (27).

FL may, however, be indirectly linked with the altered properties of collagen in both aging and diabetes. In long-lived proteins, FL undergoes further dehydration, rearrangement, and cleavage reactions, which comprise the later stages of the Maillard reaction (28-30). Many of these reactions involve oxidative processes, and their products, whose formation (in contrast to that of FL) is irreversible (26), have recently been termed "glycoxidation products" (6). Oxidation may therefore be regarded as a "fixative" of glycative damage to proteins. The intimate interrelationship between glycation and oxida-

1. Abbreviations used in this paper: $\mathrm{AER}^{24}, 24-\mathrm{h}$ albumin excretion rate; $\mathrm{CI}$, confidence interval; $\mathrm{CML}, \mathrm{N}^{\epsilon}$-(carboxymethyl)lysine; FL, fructoselysine, $\mathrm{Hb}$, hemoglobin; LJM, limitation of joint mobility; $\mathrm{MHbA}_{1}$, mean $\mathrm{HbA}_{1}$, OR, odd ratio. 
tion is further emphasized by the observation that increased glycation may, in itself, promote the formation of free radicals and therefore enhance oxidative damage to proteins and lipids (31). In collagen, glycoxidation products are insoluble, frequently pigmented or fluorescent, and include glucose-derived cross-links (6). They accumulate with advancing age $(22,23$, 32 ), and at an accelerated rate in diabetes $(22,32-36)$, paralleling the physicochemical alterations described above. In vitro, glycoxidation of collagen causes the physicochemical alterations characteristic of aging $(34,37)$. Thus, the accumulation of late Maillard or glycoxidation products may contribute significantly to the altered physical properties of collagen in both aging and diabetes $(21,33,34,36)$, and to the development of diabetic complications (32, 38-44).

In this and the accompanying study (22), FL, two glycoxidation products, $N^{\epsilon}$-( carboxymethyl) lysine (CML) $(23,45-$ $47)$ and pentosidine (32, 48-51), and Maillard-type fluorescence have been measured in skin collagen from type 1 diabetic patients. The accumulation of CML, pentosidine, and fluorescence throughout life, and their accelerated accumulation in diabetes, have been described in the preceding article (22). Here we relate the levels of FL, CML, pentosidine, and collagen-linked fluorescence, corrected for age, to the presence and severity of diabetic microvascular complications. We found significant associations between all four products and complication status. Because the levels of glycoxidation products, rather than FL, seem to determine the altered properties of collagen, our data suggest that "fixation" of initial glycative damage by free radical oxidation reactions may be implicated in the link between glycemic control and diabetic complications. Thus, in diabetic patients, individual variations in oxidative stress may modulate the consequences of hyperglycemia, and explain, in part, why the relationship between glycemic control and complications is not a simple one.

\section{Methods}

Patients. 39 patients ( 27 male/12 female) were recruited from the diabetes clinics of the Royal Victoria Hospital, Belfast, and Altnagelvin Hospital, Londonderry, Northern Ireland. All had type 1 (insulin-dependent) diabetes, diagnosed according to the criteria of the National Diabetes Data Group (52). Their mean age was 41.5 $\pm 15.3(17-73)$ yr (mean \pm 1 SD, range) and mean duration of diabetes 17.9 $\pm 11.5(0-46)$ yr. Four patients had newly diagnosed diabetes. Each patient underwent a full physical examination for the presence of diabetic complications, in addition to venous blood sampling and skin biopsy as outlined below. Nondiabetic collagen was obtained from healthy donors or at autopsy (donor age $47.6 \pm 25.9$ [0.001-85] yr) at the Royal Victoria Hospital, Belfast, as described (22).

Clinical examination. Retinal examination was performed by an ophthalmologist. The fundi were graded by the absence or presence of background or proliferative retinopathy. Blood pressure (average of three readings) was recorded using a random zero sphygmomanometer (Hawksley and Sons Ltd., Lancing, Sussex, UK) after 5 min of recumbency. Diastolic pressure was recorded at Korotkov phase V. The presence and degree of limitation of joint mobility (LJM) $(53,54)$ was assessed by placing the hand palm down on a planar surface: normally the whole palmar surface of the hand makes contact. Patients were classified into those without LJM (stage 0), those unable to make contact with any portion of only one finger, usually the proximal interphalangeal joint of the fifth (stage I), and those in whom two or more fingers were involved, usually the fourth and fifth (stage II).

Quantitative measurements of the right brachial and right and left posterior tibial pulses were made using a Doppler ultrasonic technique (average of three readings). The right brachial and right ankle measurements were expressed as a ratio (brachial/ankle systolic index). Assessment of neurological function was made by estimation of the vibration perception threshold using a biothesiometer (55) (Biomedical Instruments, Newbury, $\mathrm{OH}$ ) and expressed as the mean of three values from each lateral malleolus and the distal end of each great toe.

Hemoglobin $(\mathrm{Hb}) \mathrm{A}_{1}$ was measured by agar gel electrophoresis as previously described (26): the normal range in our laboratory is 3.6$7.2 \%$. For the entire patient group, $\mathrm{HbA}_{1}$ was $11.4 \pm 2.4(6.9-16.9) \%$ (mean $\pm 1 \mathrm{SD}$, [range]). In 24 of the 39 patients, $\mathrm{HbA}_{1}$ had been measured every 3 mo since November 1982, and for each of these, a mean $\mathrm{HbA}_{1}\left(\mathrm{MHbA}_{1}\right)$ was calculated using all values obtained during the 6 yr preceding the study. For these 24 patients, $\mathrm{MHbA}_{1}$ was $11.1 \pm 1.7$ (8.5-14.7)\%, and correlated significantly with the most recent $\mathrm{HbA}_{1}: r$ $=0.78(P<0.0001)$.

Urine collection and analysis. A single 24-h urine collection was performed at home by each patient for determination of albumin excretion rate $\left(\mathrm{AER}^{24}\right)$ in micrograms per minute. In addition, an overnight urine collection, performed within a few days of the 24-h collection, was available in 25 patients. While the categorization of patients into normoalbuminuric ( $\mathrm{AER}^{24} \leq 20 \mu \mathrm{g} / \mathrm{min}$ ), microalbuminuric ( 20 $\mu \mathrm{g} / \mathrm{min}<\mathrm{AER}^{24}<200 \mu \mathrm{g} / \mathrm{min}$ ) and "macroalbuminuric" (AER ${ }^{24}$ $\geq 200 \mu \mathrm{g} / \mathrm{min}$ ) groups was made using the 24-h urine sample, the classification was confirmed by the overnight sample in all patients in whom both urine collections were available. Any patient with a suspected or proven urinary tract infection had urinary albumin estimation deferred until urine culture was negative. Urinary albumin concentration was measured by ${ }^{125}$ I radioimmunoassay involving double separation of bound and free antigen (Diagnostic Products Ltd., Wallingford, Oxfordshire, UK). The inter- and intraassay coefficients of variation were $7 \%$ and $5 \%$, respectively, detection limit $0.9 \mu \mathrm{g} / \mathrm{ml}$.

Complication status. 14 patients had no retinopathy, 9 had background retinopathy, and 16 had proliferative retinopathy. Of 35 patients in whom AER ${ }^{24}$ was available, 26 had normoalbuminuria, 6 had microalbuminuria, and 3 had macroalbuminuria. In the macroalbuminuric group, $\mathrm{AER}^{24}$ values were 525,694 , and $1,071 \mu \mathrm{g} / \mathrm{min}$. Analysis of data involving $\mathrm{AER}^{24}$ was performed both including and excluding these macroalbuminuric values, for the statistical reasons detailed below. Of 38 patients examined for LJM, 18 had no LJM, 7 had stage I LJM, and 13 stage II LJM.

Skin sampling and analysis. Details of skin biopsy technique are provided in the accompanying paper (22). Measurements of collagen FL, CML, pentosidine, and collagen-linked fluorescence are also described briefly in the accompanying article (22), and in detail elsewhere $(23,45-47)$. Laboratory analyses of the collagen samples were performed without prior knowledge of sample identity. The correlations between collagen $\mathrm{FL}$ and $\mathrm{HbA}_{1}$ and between $\mathrm{FL}$ and $\mathrm{MHbA}_{1}$ were highly significant $(r=0.74$ and $r=0.89$, respectively $(P$ $<0.0001)$ ), confirming previous findings $(24,25)$. The study was approved by the Ethical Committees of the participating hospitals and by the Human Subjects Review Board at the University of South Carolina.

Statistical analysis. Data processing and statistical analyses were performed using the Statistical Analysis System (SAS). Each of the early and late products of glycation was examined according to the presence and / or severity of a specific diabetic complication by a Kruskal-Wallis one-way analysis of variance. The relationships among $\mathrm{HbA}_{1}, \mathrm{MHbA}_{1}$, and FL were examined using the Pearson correlation coefficient, in that these variables were considered to be normally distributed. For analyses involving urinary albumin data (which was not normally distributed), a Spearman correlation coefficient was used. Analyses of data involving $\mathrm{AER}^{24}$ were performed both including and excluding results for the three macroalbuminuric patients. This was done in case bias should result from the high, "outlying," AER ${ }^{24}$ values ( $>2$ SD from the mean for all patients) in these patients. Although the inclusion of results for the macroalbuminuric patients tended to increase the level of significance in some analyses, in general, the results and conclusions were similar with or without these patients. Multiple 
Table I. Retinopathy Status and Levels of Maillard Products in Skin Collagen

\begin{tabular}{|c|c|c|c|c|c|c|c|}
\hline & $n$ & No retinopathy & $n$ & $\begin{array}{l}\text { Background } \\
\text { retinopathy }\end{array}$ & $n$ & $\begin{array}{l}\text { Proliferative } \\
\text { retinopathy }\end{array}$ & $P$ \\
\hline Age $(y r)$ & 14 & $\begin{array}{c}37.5 \pm 16.1 \\
(17-65)\end{array}$ & 9 & $\begin{array}{c}46.3 \pm 15.6 \\
(29-73)\end{array}$ & 16 & $\begin{array}{l}41.7 \pm 14.5 \\
(22-68)\end{array}$ & NS \\
\hline Duration $(y r)$ & 14 & $\begin{array}{c}{ }^{ \pm} 10.6 \pm 10.5 \\
(0-38)\end{array}$ & 9 & $\begin{array}{c}123.5 \pm 10.4 \\
(8-37)\end{array}$ & 16 & $\begin{array}{c}* * 21.4 \pm 10.1 \\
(10-46)\end{array}$ & $<0.01$ \\
\hline $\mathrm{HbA}_{1}(\%)$ & 14 & $\begin{array}{l}11.1 \pm 2.1 \\
(8.0-15.4)\end{array}$ & 8 & $\begin{array}{l}10.5 \pm 2.3 \\
(6.9-14.2)\end{array}$ & 16 & $\begin{array}{r}12.1 \pm 2.7 \\
(8.7-16.9)\end{array}$ & NS \\
\hline $\mathrm{MHbA}_{1}(\%)$ & 4 & $\begin{array}{l}10.3 \pm 2.0 \\
(8.5-13.1)\end{array}$ & 7 & $\begin{array}{l}10.7 \pm 1.3 \\
(9.3-12.8)\end{array}$ & 13 & $\begin{array}{r}11.6 \pm 1.7 \\
(9.1-14.7)\end{array}$ & NS \\
\hline $\mathrm{FL}^{\mathbf{R}}$ & 14 & $\begin{array}{l}\ddagger 2.79 \pm 1.02 \\
(1.84-5.09)\end{array}$ & 8 & $\begin{array}{r}3.32 \pm 0.41 \\
(2.60-3.80)\end{array}$ & 15 & $\begin{array}{l}* * 3.76 \pm 1.16 \\
(2.32-5.87)\end{array}$ & $<0.05$ \\
\hline $\mathrm{CML}^{\mathrm{R}}$ & 14 & $\begin{array}{r}{ }^{8} 1.17 \pm 0.35 \\
(0.60-1.76)\end{array}$ & 8 & $\begin{array}{l}{ }_{1} 1.54 \pm 0.25 \\
(1.30-1.93)\end{array}$ & 15 & $\begin{array}{c}1 \pm \$ 1.86 \pm 0.34 \\
(1.33-2.37)\end{array}$ & $<0.001$ \\
\hline Pentosidine $^{\mathbf{R}}$ & 12 & $\begin{array}{l}* 1.25 \pm 0.60 \\
(0.52-2.47)\end{array}$ & 6 & $\begin{array}{r}1.73 \pm 0.51 \\
(1.38-2.38)\end{array}$ & 11 & $\begin{array}{c}1.84 \pm 0.57 \\
(1.07-2.83)\end{array}$ & $<0.05$ \\
\hline Fluorescence $^{\mathbf{R}}$ & 11 & $\begin{array}{l}{ }^{\ddagger} 1.17 \pm 0.26 \\
(0.84-1.65)\end{array}$ & 6 & $\begin{array}{r}1.36 \pm 0.27 \\
(1.09-1.76)\end{array}$ & 10 & $\begin{array}{l}* * 1.55 \pm 0.25 \\
(1.20-1.91)\end{array}$ & $<0.01$ \\
\hline
\end{tabular}

Data are given as means \pm 1 SD (range); NS, $P>0.05$. $P$ statistical analysis is performed using Kruskall-Wallis one-way analysis of variance. Superscript " $R$ " denotes age-corrected ratio. ${ }^{*} P<0.05$ compared to any retinopathy; ${ }^{\ddagger} P<0.01$ compared to any retinopathy; $\$ P<0.001$ compared to any retinopathy; " $P<0.05$ compared to no retinopathy; ' $P<0.05$ compared to no retinopathy; ${ }^{* *} P<0.01$ compared to no retinopathy; ${ }^{\ddagger \ddagger} P<0.001$ compared to no retinopathy; ${ }^{\$} P<0.05$ compared to grade 1 retinopathy.

logistic regression analysis (56) was used to test several models of the association of a specific complication with the Maillard products, controlling for age, sex, and duration of diabetes. For descriptive purposes in tables and text, the arithmetic mean \pm 1 SD is quoted. The conventional level of significance $(P<0.05)$ has been used in all analyses.

Measurements of collagen FL, CML, pentosidine, and fluorescence were corrected for the recognized increase with age $(22,23)$ by expressing the observed value as a ratio of the predicted value for a control patient of the same age (derived from the corresponding regression line in the control population [22]). These calculated ratios are denoted by the superscript " $R$ " (e.g., $\left.C M L^{R}\right)$. As the concentration of FL rises rapidly in early life, but is only weakly related to age after age $20 \mathrm{yr}$, the regression line for FL was estimated from the data for nondiabetic control subjects between the ages of 20 and $85 \mathrm{yr}$. In some cases $(<10 \%$ of samples) insufficient collagen was available for all assays to be performed. Consequently, there is some variation in the number of measurements between analyses.

\section{Results}

The mean age, duration of diabetes, $\mathrm{HbA}_{1}, \mathrm{MHbA}_{1}$, and levels of each of the Maillard products across the various grades of retinopathy, nephropathy, and limited joint mobility are shown in Tables I-III and Fig. 1-3.

Patients in the three retinopathy categories did not differ significantly in age whether considered collectively (by analysis of variance) or between subgroups (Table I). The severity of retinopathy was related to the duration of diabetes $(P<0.01)$. There was no association between $\mathrm{HbA}_{1}$ or $\mathrm{MHbA}_{1}$ values and retinopathy status. In contrast, age-corrected levels of skin collagen FL, CML, pentosidine, and Maillard-type fluorescence all increased progressively and significantly with the severity of retinopathy (Table I, Fig. 1). These increases were most significant for CML $(P<0.001)$ and for collagen-linked fluorescence $(P<0.01)$.
Compared with normoalbuminuric patients, patients with $\mathrm{AER}^{24} \geq 20 \mu \mathrm{g} / \mathrm{min}$ were of slightly greater age and duration of diabetes, and their $\mathrm{HbA}_{1}, \mathrm{MHbA}_{1}$, and collagen FL content also tended to be higher: however, none of these differences reached significance ( Table II). In contrast, age-corrected levels of skin collagen FL, CML, pentosidine, and fluorescence were significantly higher in patients with $\mathrm{AER}^{24} \geq 20 \mu \mathrm{g} / \mathrm{min}$ than in normoalbuminuric patients (Table II, Fig. 2). If data for the three macroalbuminuric patients were excluded from these analyses, age-corrected CML, pentosidine, and fluorescence remained significantly elevated in microalbuminuric compared with normoalbuminuric patients $(P<0.05, P$ $<0.05, P<0.01$, respectively), but the difference in FL levels

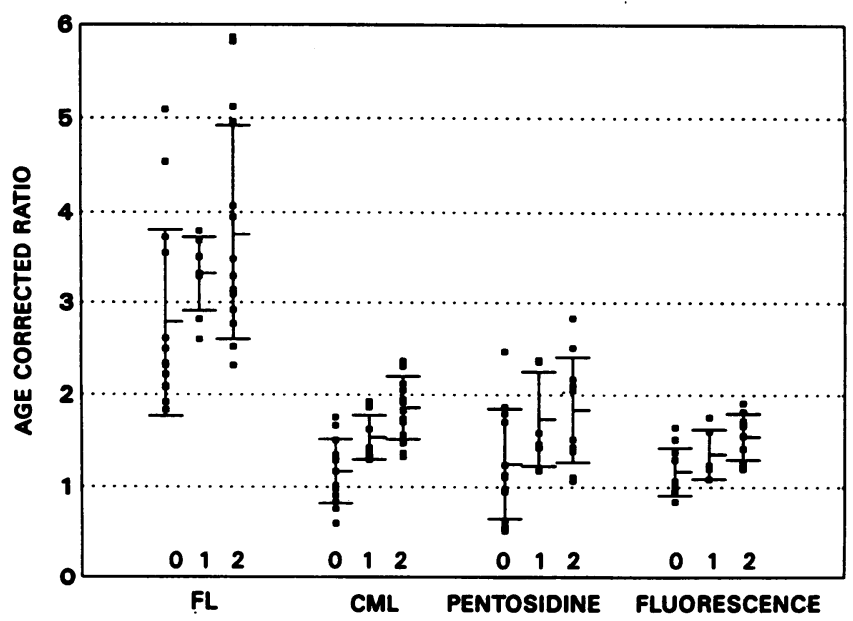

Figure 1. Maillard products in skin collagen and retinopathy status. Grade 0, no retinopathy; grade 1, background retinopathy; grade 2, proliferative retinopathy. Bars show mean \pm 1 SD in each category. 
Table II. AER ${ }^{24}$ and Levels of Maillard Products in Skin Collagen

\begin{tabular}{|c|c|c|c|c|c|}
\hline & $n$ & $\begin{array}{c}\mathrm{AER}^{24} \\
<20 \mu \mathrm{g} / \mathrm{min}\end{array}$ & $n$ & $\begin{array}{c}\mathrm{AER}^{24} \\
\geq 20 \mu \mathrm{g} / \mathrm{min}\end{array}$ & $P$ \\
\hline Age $(y r)$ & 27 & $\begin{array}{c}41.9 \pm 14.6 \\
(17-68)\end{array}$ & 9 & $\begin{array}{c}44.6 \pm 16.9 \\
(23-73)\end{array}$ & NS \\
\hline Duration $(y r)$ & 27 & $\begin{array}{c}17.2 \pm 12.2 \\
(0-46)\end{array}$ & 6 & $\begin{array}{r}22.9 \pm 9.0 \\
(17-42)\end{array}$ & NS \\
\hline $\mathrm{HbA}_{1}(\%)$ & 26 & $\begin{array}{l}10.8 \pm 1.9 \\
(6.9-15.4)\end{array}$ & 6 & $\begin{array}{l}13.0 \pm 3.3 \\
(8.7-16.9)\end{array}$ & NS \\
\hline $\mathrm{MHBA}_{1}(\%)$ & 17 & $\begin{array}{l}10.8 \pm 1.5 \\
(8.5-13.3)\end{array}$ & 7 & $\begin{array}{l}11.8 \pm 1.9 \\
(9.1-14.7)\end{array}$ & NS \\
\hline $\mathrm{FL}^{\mathrm{R}}$ & 25 & $\begin{array}{c}3.00 \pm 0.92 \\
(1.84-5.12)\end{array}$ & 9 & $\begin{array}{c}3.99 \pm 1.28 \\
(2.32-5.87)\end{array}$ & $<0.05$ \\
\hline $\mathrm{CML}^{\mathrm{R}}$ & 25 & $\begin{array}{c}1.37 \pm 0.36 \\
(0.60-2.12)\end{array}$ & 9 & $\begin{array}{c}1.99 \pm 0.31 \\
(1.43-2.37)\end{array}$ & $<0.001$ \\
\hline Pentosidine $^{\mathbf{R}}$ & 21 & $\begin{array}{c}1.41 \pm 0.56 \\
(0.52-2.47)\end{array}$ & 6 & $\begin{array}{c}2.29 \pm 0.32 \\
(2.05-2.83)\end{array}$ & $<0.01$ \\
\hline Fluorescence $\mathrm{e}^{\mathbf{R}}$ & 20 & $\begin{array}{c}1.29 \pm 0.23 \\
(0.96-1.76)\end{array}$ & 6 & $\begin{array}{c}1.73 \pm 0.12 \\
(1.56-1.91)\end{array}$ & $<0.01$ \\
\hline
\end{tabular}

Data are given as means \pm SD (range); NS, $P>0.05$. $P$ statistical analysis is performed using Mann-Whitney $U$ test. Superscript " $R$ " denotes age-corrected ratio.

was no longer statistically significant. When $\mathrm{AER}^{24}$ results from all patients were analyzed together using the nonparametric Spearman correlation coefficient, there were significant correlations between $\mathrm{AER}^{24}$ and $\mathrm{MHbA}_{1}, \mathrm{FL}^{\mathrm{R}}, \mathrm{CML}^{\mathrm{R}}$, pentosidine $^{R}$, and fluorescence ${ }^{R}$ ( Table IV). Exclusion of the three macroalbuminuric patients from these analyses decreased the correlations between $\mathrm{AER}^{24}$ and glycoxidation products $\left(\mathrm{CML}^{\mathrm{R}}, r=0.33\right.$; pentosidine ${ }^{\mathrm{R}}, r=0.38$; fluorescence ${ }^{\mathrm{R}}, r$
$=0.38($ all $P=0.06))$, and $\mathrm{MHbA}_{1}$, and only the correlation between $\mathrm{AER}^{24}$ and $\mathrm{FL}^{\mathrm{R}}$ remained significant $(r=0.44, P$ $<0.05$ ). If patients with micro- and macroalbuminuria were considered together as a separate group $(n=9)$, none of the glycation products correlated significantly with $\mathrm{AER}^{24}$.

Patients with LJM (Table III) had a longer duration of diabetes than those without $(P<0.01)$ (also significant between grade 0 and grade 2 LJM, $P<0.01$, and grade 1 and 2 LJM, $P<0.05$ ). $\mathrm{HbA}_{1}, \mathrm{MHbA}_{1}$, and age-corrected collagen FL values were similar between these categories. Age-corrected CML, pentosidine, and Maillard-type fluorescence tended to increase with more severe LJM (Table III, Fig. 3) but this was significant only for pentosidine and fluorescence, and only between patients with grade 0 and grade 2 disease $(P<0.05)$. In these analyses (unlike the logistic regression models described below), the Maillard products were not corrected for duration of diabetes: the observation that age-adjusted pentosidine and fluorescence showed the greatest correlations with duration of diabetes (22) may be pertinent to these findings.

CML, pentosidine, and fluorescence correlated with systolic blood pressure, but no significant association was found after the products were corrected for age. There was a significant correlation between age-corrected CML and the brachialankle systolic index $(r=-0.51, P=0.05)$, but this was not observed with pentosidine or fluorescence. None of the products, after correction for age, correlated with measurements of either ankle or toe vibration perception threshold.

The effect of each of the Maillard products on a specific complication of diabetes was examined using logistic regression analysis. For each complication (defined as either present or absent), serial models were examined containing a Maillard product while simultaneously controlling for age, sex, and duration of diabetes ( Tables V and VI). The unavailability of some data points, particularly for pentosidine and fluorescence, decreased the power of their respective models. The addition of

Table III. LJM and Levels of Maillard Reaction Products in Skin Collagen

\begin{tabular}{|c|c|c|c|c|c|c|c|}
\hline & $n$ & $\begin{array}{l}\text { LJM absent } \\
\text { (grade 0) }\end{array}$ & $n$ & $\begin{array}{l}\text { LJM present } \\
\text { (grade 1) }\end{array}$ & $n$ & $\begin{array}{l}\text { LJM present } \\
\text { (grade 2) }\end{array}$ & $P$ \\
\hline Age $(y r)$ & 18 & $\begin{array}{l}38.7 \pm 15.2 \\
(17-63)\end{array}$ & 7 & $\begin{array}{c}39.9 \pm 15.9 \\
(22-65)\end{array}$ & 13 & $\begin{array}{l}45.3 \pm 15.9 \\
(23-73)\end{array}$ & NS \\
\hline Duration $(y r)$ & 18 & $\begin{array}{c}* 12.6 \pm 8.9 \\
(0-27)\end{array}$ & 7 & $\begin{array}{r}15.9 \pm 4.6 \\
(11-24)\end{array}$ & 13 & $\begin{array}{c}8.1126 .5 \pm 12.9 \\
(0-46)\end{array}$ & $<0.01$ \\
\hline $\mathrm{HbA}_{1}$ & 17 & $\begin{array}{l}11.5 \pm 2.0 \\
(8.0-16.9)\end{array}$ & 7 & $\begin{array}{l}11.5 \pm 2.8 \\
(6.9-16.7)\end{array}$ & 13 & $\begin{array}{l}11.5 \pm 3.0 \\
(6.9-16.7)\end{array}$ & NS \\
\hline $\operatorname{MHbA}_{1}(\%)$ & 11 & $\begin{array}{l}11.4 \pm 2.0 \\
(8.5-14.7)\end{array}$ & 5 & $\begin{array}{c}11.7 \pm 1.4 \\
(10.2-13.3)\end{array}$ & 7 & $\begin{array}{c}10.5 \pm 0.9 \\
(9.1-11.6)\end{array}$ & NS \\
\hline $\mathrm{FL}^{\mathrm{R}}$ & 17 & $\begin{array}{r}3.43 \pm 1.21 \\
(1.92-5.82)\end{array}$ & 6 & $\begin{array}{c}3.46 \pm 0.92 \\
(2.22-4.54)\end{array}$ & 13 & $\begin{array}{c}3.09 \pm 0.98 \\
(1.84-5.87)\end{array}$ & NS \\
\hline $\mathrm{CML}^{\mathrm{R}}$ & 17 & $\begin{array}{r}1.41 \pm 0.45 \\
(0.60-2.35)\end{array}$ & 6 & $\begin{array}{c}1.63 \pm 0.60 \\
(0.91-2.37)\end{array}$ & 13 & $\begin{array}{r}1.66 \pm 0.36 \\
(1.02-2.31)\end{array}$ & NS \\
\hline Pentosidine $^{R}$ & 13 & $\begin{array}{r}1.36 \pm 0.56 \\
(0.52-2.17)\end{array}$ & 5 & $\begin{array}{c}1.44 \pm 0.62 \\
(0.95-2.51)\end{array}$ & 10 & $\begin{array}{c}{ }^{ \pm} 1.96 \pm 0.59 \\
(1.11-2.83)\end{array}$ & NS \\
\hline Fluorescence $^{\mathbf{R}}$ & 13 & $\begin{array}{r}1.27 \pm 0.30 \\
(0.84-1.90)\end{array}$ & 4 & $\begin{array}{c}1.29 \pm 0.37 \\
(1.02-1.82)\end{array}$ & 9 & $\begin{array}{c}{ }^{\ddagger} 1.52 \pm 0.24 \\
(1.07-1.76)\end{array}$ & NS \\
\hline
\end{tabular}

Data are given as means $\pm \mathrm{SD}$ (range); NS, $P>0.05$. P statistical analysis is performed using the Mann-Whitney U test. Superscript "R" denotes age-corrected ratio. ${ }^{*} P<0.05$ compared to the presence of $\mathrm{LJM} ;{ }^{\ddagger} P<0.05$ grade $2 \mathrm{LJM}$ compared to grade $0 \mathrm{LJM} ;{ }^{\S} P<0.01$ grade 2 LJM compared to grade $0 \mathrm{LJM}$; $P<0.05$ grade $1 \mathrm{LJM}$ compared to grade $2 \mathrm{LJM}$. 


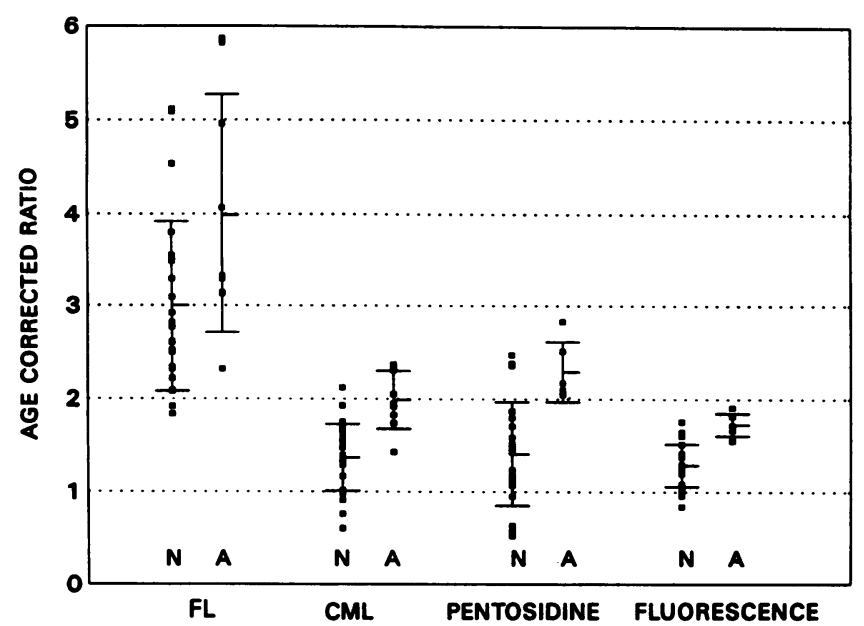

Figure 2. Maillard products in skin collagen and albumin excretion rate. $N$, normoalbuminuria ( $\mathrm{AER}^{24}<20 \mu \mathrm{g} / \mathrm{min}$ ); $A$, nephropathy (as defined in text) $\left(\mathrm{AER}^{24} \geq 20 \mu \mathrm{g} / \mathrm{min}\right)$. Bars show mean $\pm 1 \mathrm{SD}$ in each category.

either $\mathrm{HbA}_{1}$ or $\mathrm{MHbA}_{1}$ made no further contribution to any model, and so neither was included in the analyses.

Skin collagen FL and CML were significant independent variables associated with the presence of retinopathy (Table V). A $20 \%$ increment in FL or CML was associated with an increased odds of retinopathy (FL odds ratio $(O R)=1.06,95 \%$ confidence interval (CI) 1.01-1.12, $P<0.05$; $\mathrm{CML} \mathrm{OR}=6.77$; 95\% CI 1.33-34.56, $P<0.05)$. In smaller models, similarly controlling for age, sex, and duration of diabetes, neither pentosidine nor fluorescence was associated with retinopathy, although fluorescence approached significance: for a $20 \%$ increment in fluorescence the OR was 2.37 (95\%CI 0.98-5.20), $P$ $=0.05$.

Skin collagen FL and CML were also significant independent variables associated with the presence of early nephropathy ( $\mathrm{AER}^{24} \geq 20 \mu \mathrm{g} / \mathrm{min}$ ) (Table VI). A 20\% increment in FL or CML was associated with an increased odds of early nephropathy (FL OR $=1.05,95 \% \mathrm{CI} 1.01-1.10, P<0.05$; CML $\mathrm{OR}=13.44,95 \%$ CI 2.00-93.30, $P<0.01$ ). Pentosidine approached significance as an independent variable associated with early nephropathy $(\mathrm{OR}=1.11,95 \%$ CI $1.00-1.23, P$ $=0.05$ ). If the three macroalbuminuric patients were excluded from the analyses, only CML emerged as a significant independent variable associated with microalbuminuria $(O R=9.70$,

Table IV. AER ${ }^{24}$ : Correlations with Levels of Maillard Products in Skin Collagen

\begin{tabular}{lccc}
\hline & $r^{*}$ & $P$ & $n$ \\
\hline $\mathrm{HbA}_{1}(\%)$ & 0.33 & 0.055 & 35 \\
$\mathrm{MHbA}_{1}(\%)$ & 0.49 & 0.016 & 24 \\
$\mathrm{FL}^{\mathrm{R}}$ & 0.52 & 0.002 & 34 \\
$\mathrm{CML}^{\mathrm{R}}$ & 0.44 & 0.009 & 34 \\
Pentosidine $^{\mathrm{R}}$ & 0.44 & 0.022 & 27 \\
Fluorescence $^{\mathrm{R}}$ & 0.47 & 0.016 & 26 \\
\hline
\end{tabular}

Superscript " $R$ " denotes age-corrected ratio. * Spearman correlation coefficients.

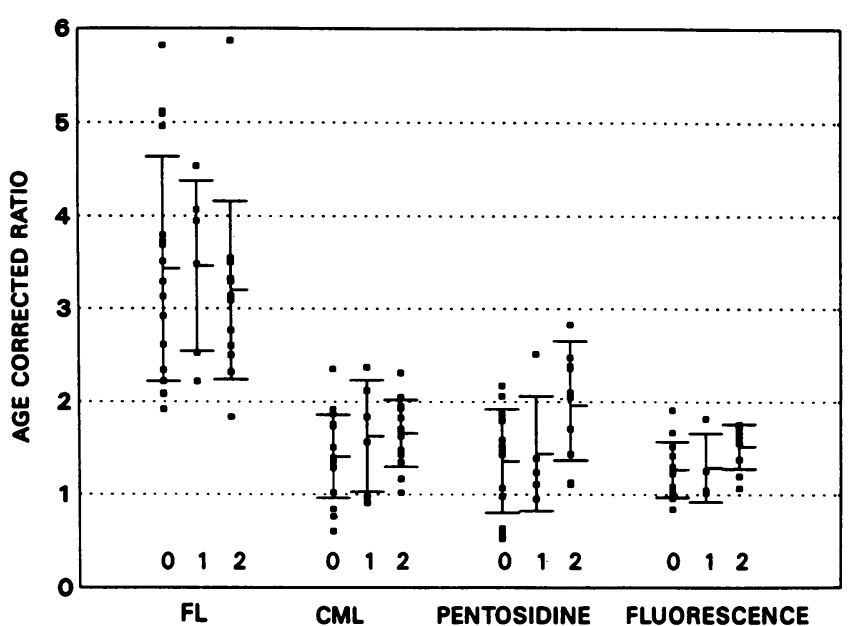

Figure 3. Maillard products in skin collagen and grade of LJM. Grades of LJM are defined in the text. Bars show mean \pm 1 SD in each category.

95\%CI $1.48-63.53, P<0.01)$, with pentosidine again approaching significance $(\mathrm{OR}=1.12,95 \% \mathrm{CI} 0.99-1.26, P$ $=0.07$ ). None of the Maillard products was independently associated with limited joint mobility.

Table V. Retinopathy Status and Levels of Maillard Products in Skin Collagen, Controlled for Age, Sex, and Duration of Diabetes: Multiple Logistic Regression Models

\begin{tabular}{|c|c|c|c|c|}
\hline \multirow[b]{2}{*}{ Variable } & \multicolumn{4}{|c|}{ Dependent variable: Retinopathy (present/absent) } \\
\hline & $\begin{array}{l}\text { Parameter } \\
\text { estimate }\end{array}$ & SE & $x^{2}$ & $P$ \\
\hline Intercept & -3.40 & 1.91 & 3.18 & 0.07 \\
\hline Age $(y r)$ & -0.07 & 0.05 & 2.45 & 0.12 \\
\hline Sex & -1.79 & 1.14 & 2.47 & 0.12 \\
\hline Duration (yr) & 0.20 & 0.07 & 7.38 & 0.01 \\
\hline $\mathrm{FL}^{*}$ & 0.30 & 0.13 & 4.92 & 0.03 \\
\hline Intercept & -0.04 & 1.44 & 0.01 & 0.98 \\
\hline Age $(y r)$ & -0.26 & 0.11 & 5.54 & 0.02 \\
\hline Sex & -2.04 & 1.35 & 2.31 & 0.12 \\
\hline Duration $(y r)$ & 0.12 & 0.07 & 3.18 & 0.07 \\
\hline $\mathrm{CML}^{*}$ & 9.57 & 4.16 & 5.29 & 0.02 \\
\hline Intercept & 0.42 & 1.46 & 0.09 & 0.77 \\
\hline Age $(y r)$ & -0.08 & 0.07 & 1.50 & 0.22 \\
\hline Sex & -1.43 & 0.97 & 2.18 & 0.14 \\
\hline Duration $(y r)$ & 0.13 & 0.07 & 3.52 & 0.06 \\
\hline Pentosidine $^{\ddagger}$ & 0.06 & 0.08 & 0.69 & 0.41 \\
\hline Intercept & 0.39 & 1.44 & 0.07 & 0.79 \\
\hline Age $(y r)$ & -0.21 & 0.10 & 4.40 & 0.04 \\
\hline Sex & -2.62 & 1.39 & 3.58 & 0.06 \\
\hline Duration (yr) & 0.11 & 0.07 & 2.81 & 0.09 \\
\hline Fluorescence $^{\ddagger}$ & 4.10 & 2.11 & 3.77 & 0.05 \\
\hline
\end{tabular}

* Two observations were missing from the model containing FL and CML. ${ }^{\ddagger}$ Seven observations were missing from each of the models containing pentosidine and fluorescence. 
Table VI. AER ${ }^{24}$ and Levels of Maillard Products in Skin Collagen, Controlled for Age, Sex, and Duration of Diabetes: Multiple Logistic Regression Models

\begin{tabular}{lcccc}
\hline & \multicolumn{4}{c}{ Dependent variable: $\mathrm{AER}^{24} \geq \mu \mathrm{g} / \mathrm{min}$ (present/absent) } \\
\cline { 2 - 5 } \multicolumn{1}{c}{ Variable } & $\begin{array}{l}\text { Parameter } \\
\text { estimate }\end{array}$ & $\mathrm{SE}$ & $\chi^{2}$ & $P$ \\
\hline Intercept & -5.42 & 2.34 & 5.37 & 0.02 \\
Age $(y r)$ & -0.02 & 0.04 & 0.40 & 0.53 \\
Sex & 0.06 & 1.00 & 0.01 & 0.95 \\
Duration $(y r)$ & 0.07 & 0.06 & 1.59 & 0.21 \\
FL* & 0.25 & 0.11 & 4.77 & 0.03 \\
& & & & \\
Intercept & -4.53 & 2.55 & 3.15 & 0.08 \\
Age $(y r)$ & -0.27 & 0.10 & 6.76 & 0.01 \\
Sex & 1.72 & 1.32 & 1.70 & 0.19 \\
Duration $(y r)$ & -0.10 & 0.08 & 1.46 & 0.23 \\
CML* & 13.15 & 4.87 & 7.28 & 0.007 \\
Intercept & & & & \\
Age $(y r)$ & 4.18 & 3.46 & 1.46 & 0.23 \\
Sex & -0.44 & 0.24 & 3.48 & 0.06 \\
Duration $(y r)$ & 1.15 & 1.35 & 0.72 & 0.40 \\
Pentosidine & -0.24 & 0.16 & 2.28 & 0.13 \\
& 0.52 & 0.27 & 3.82 & 0.05 \\
\hline
\end{tabular}

* Five observations were missing from each of the models containing FL and CML. ${ }^{\ddagger} 10$ observations were missing from each of the models containing pentosidine and fluorescence. Convergence was not obtained with the model containing fluorescence after 1,000 iterations.

\section{Discussion}

Several studies have reported a link between Maillard reaction products in collagen and the complications of diabetes (32, $41-44,49)$. In some, levels of discrete products $(32,42,43,49)$ were related to a single complication $(42,43,49)$; in others, the conclusions were inferred from analyses of measurements of collagen-linked fluorescence $(41,44)$. It is now recognized that nonglycation products, such as those derived from lipid peroxidation, have similar fluorescence spectra to carbohydrate-derived Maillard products. Because these nonglycation compounds may become covalently bound to collagen, they may contribute to total collagen fluorescence $(44,57,58)$. A strength of the present study is the focus on structurally characterized products of the Maillard reaction which have been identified in glycated proteins both in vitro and in vivo.

As summarized in Figs. 1-3, both early (FL) and late (CML, pentosidine, and fluorescence) Maillard products in skin collagen increased with the presence and severity of diabetic retinopathy. In each case there was a significant increase between patients with grade 0 and grade 2 retinopathy, and for CML between grade 0 and grade 1 , and between grade 1 and grade 2 , disease. These and other data discussed below are consistent with a pathophysiological role for glycation and glycoxidation of proteins in diabetic retinopathy, and suggest that the extent of modification of collagen in skin may be indicative of the level of damage in other tissues, including perhaps, retinal capillary basement membrane proteins. In accordance with our findings, an increase in age-adjusted skin collagen pentosidine levels with increasing severity of retinopathy was recently reported by Sell et al. (32). The relevance of age and duration of diabetes both to the development of complications and to the levels of glycoxidation products in skin collagen is evident in the present study and the preceding article (22). Controlling for these variables, both skin collagen FL and CML content remained independently associated with retinopathy, and the association of fluorescence with retinopathy approached significance $(P=0.05)($ Table $\mathrm{V})$. Unavailable patient data and the stronger correlation of pentosidine than the other products with duration of diabetes (22) may have contributed to the failure of pentosidine to predict retinopathy, even though it increased significantly across the various grades of retinopathy.

It was somewhat surprising that $\mathrm{HbA}_{1}$ and mean $\mathrm{HbA}_{1}$, in contrast to collagen FL, were not associated with retinopathy, particularly in light of previous findings (12). Monnier et al. (41) also failed to find a correlation between $\mathrm{HbA}_{1}$ and retinopathy. The discrepancy between this and the previous study (12) may reflect a smaller variation in glycemia, differing patient characteristics, and a smaller patient cohort than reported previously.

Another new, and potentially important finding is the increase in concentrations of age-corrected FL, CML, pentosidine, and Maillard-type fluorescence in skin collagen from patients with early nephropathy compared with those who had normal albumin excretion. For the glycoxidation products and fluorescence, these increases remained significant when the microalbuminuric patients alone were compared with those who had normal albumin excretion. Using a less stringent definition of nephropathy (daily protein excretion $>0.5 \mathrm{~g}$ ), Monnier, Sell, and co-workers have previously described trends towards increased skin collagen pentosidine (32) and fluorescence (41) in nephropathic compared to nonnephropathic diabetic patients, but the differences were not statistically significant. In the present study, both early and late glycation products, and $\mathrm{MHbA}_{1}$, correlated with $\mathrm{AER}^{24}$ in the entire patient group (Table IV). The lack of correlation between these products and $\mathrm{AER}^{24}$ in the nine patients whose $\mathrm{AER}^{24}$ exceeded $20 \mu \mathrm{g} / \mathrm{min}$ is of uncertain significance, inasmuch as there is little power to show an effect in such a small number of patients. Controlling for age and duration of diabetes using logistic regression analyses, FL and CML were independently associated with the presence of nephropathy, and pentosidine approached significance $(P=0.05)$ (Table VI). These findings suggest that if the accumulation of glycation and glycoxidation products in skin collagen is reflected in renal tissue proteins, then these modifications may be relevant to the earliest stages of diabetic nephropathy. Putatively, modification of glomerular basement membranes could contribute to altered permeability, initially through charge-dependent mechanisms such as a decrease in anionic proteoglycans and immobilization of plasma proteins, later progressing to permanent structural damage and alteration of pore size (40). Also, the ability of advanced Maillard products to quench the vasodilator (59) and antiproliferative (60) effects of nitric oxide has recently been recognized, and may be implicated in the pathogenesis of diabetic nephropathy (60).

Two recent studies have estimated Maillard products in both diabetic and control subjects with varying degrees of renal impairment. In one (49), pentosidine was measured in skin collagen, while in the other (43) a new whole-cell macrophage ligand-binding assay was used to provide a quantitative esti- 
mate of the concentration of Maillard products in both serum and arterial tissue proteins. Both studies demonstrated significant accumulation of these products in patients with end-stage renal failure, whether or not diabetes was present. Sell and Monnier (49) found no increase in pentosidine in skin collagen from nonnephropathic type 2 (non-insulin-dependent) diabetic patients compared with nondiabetic control subjects. However, in a more recent study (32), they reported increased pentosidine levels (more than twofold) in nonnephropathic type 1 (insulin-dependent) diabetic patients compared with control subjects. Our findings, in agreement with the latter study, suggest that the increase in pentosidine (and other Maillard products) is a characteristic of the diabetic population in general, and is not confined to patients with renal disease.

The significance of limitation of joint mobility in diabetes remains unclear. In the present study, there was a tendency for the Maillard products to increase with the severity of LJM, but the increase was significant only for age-corrected pentosidine and fluorescence and only between grades 0 and 2 LJM. Sell, Monnier, and co-workers also found significant associations between both pentosidine (32) and fluorescence (41) and the presence of LJM. However, in our study, by using logistic regression analysis to control for duration of diabetes, no significant associations between Maillard products and LJM remained, and in previous (unpublished) findings, we were unable to find a correlation between LJM and long-term glycemic control (serial $\mathrm{HbA}_{1}$ measurements over a 6 -yr period). In the present study, neurologic function, as evidenced by measurements of ankle and toe vibration perception threshold, was unrelated to levels of Maillard products in skin collagen. This is consistent with the thesis that other processes, such as osmotic effects from increased sorbitol pathway activity, may be of greater relevance than protein glycoxidation to the development of diabetic neuropathy.

Although correlations were found between levels of Maillard products and arterial blood pressure, these did not persist after correction for age. Unlike Monnier et al. (41), we found no association of blood pressure with severity of retinopathy, nor with the presence of early nephropathy. Age-corrected CML was weakly associated with the brachial-ankle systolic index. A related finding by Monnier et al. (41), correlating collagen-linked fluorescence and arterial stiffness, supports the conclusion that widespread collagen browning may be implicated in the development of diabetic macrovascular disease.

It is acknowledged that with the small number of patients in the present study, the results of logistic regression analysis must be interpreted with caution. However, when considered together with the significant mean differences across the various complication subgroups, the findings are consistent with a role for glycation and glycoxidation of proteins in the development of the microvascular complications of diabetes. The independent association of skin collagen FL with diabetic retinopathy and early nephropathy may imply a direct pathogenic role for glycated structural proteins in the affected tissues. However, any explanation must take into account the fact that FL levels in collagen rise rapidly after the onset of diabetes and that the increase is reversible with short-term improvements in glycemic control (26). In contrast, complications develop only slowly over a period of years. Alternative explanations for the association between increased collagen FL and the development of complications include the possibility that chronic hy- perglycemia leads to both consequences through entirely separate mechanisms, or, as we suggest, that the link may be indirect, inasmuch as in addition to glycation, oxidation is necessary to produce permanent alterations to proteins (37). The latter hypothesis is supported by studies using aminoguanidine, which does not influence FL formation, but which inhibits collagen cross-linking in vivo (61) and the formation of CML and pentosidine in vitro (Fu et al., manuscript in preparation). In animal models, aminoguanidine has been shown to retard the development of diabetic retinopathy (62), nephropathy (63), and neuropathy (64).

As with collagen FL, the finding of increased concentrations of glycoxidation products in association with diabetic complications does not prove a causal relationship. Glycoxidation may be only one of perhaps several, possibly interrelated mechanisms (65) altering the properties not just of collagen, but also of other extracellular matrix constituents: abnormalities of protein synthesis, hydroxylation and turnover have been described (66-68). The pathophysiological relevance of glycoxidation products in diabetes is also controversial on quantitative grounds. CML and pentosidine are present in little more than trace amounts in collagen. Despite this, they may be regarded as biomarkers of total glycoxidative damage (6), most of which results in the formation of other products whose chemical structures are, as of now, uncharacterized.

If the accumulation of glycoxidation products does indeed contribute to the development of diabetic complications, then the ability of an individual to resist oxidative stress may modulate the consequences of hyperglycemia. Prospective studies are needed to determine whether those diabetic patients who accumulate glycoxidation products unusually rapidly (controlling for long-term glycemia), i.e., subjects with the weakest antioxidant defense mechanisms, represent a subgroup which is particularly vulnerable to the development of complications. In the future, inhibition not only of glycation (by improved glycemic control), but also of oxidative stress (by dietary and pharmacologic manipulations), may offer a logical approach to the prevention of diabetic complications.

\section{Acknowledgments}

The authors wish to thank Professor D. R. Hadden, Dr. L. Kennedy, and Dr. A. B. Atkinson (Royal Victoria Hospital), and Drs. D. A. J. Keegan, F. A. O'Connor, and W. E. Parkes (Altnagelvin Hospital) for permission to study patients under their care. We are also grateful to the staff of the Biochemistry and Hematology Departments at the Royal Victoria and Altnagelvin Hospitals, to Professor D. B. Archer for performing the ophthalmological assessments, to Drs. D. J. Pettitt and R. L. Hanson for statistical advice, and to Drs. D. J. Pettitt and P. H. Bennett for helpful discussions.

This work was supported in part by research grant DK-19971 from the National Institute of Diabetes, Digestive and Kidney Diseases.

\section{References}

1. Jarrett, R. J., H. Keen, and R. Chakrabarti. 1982. Diabetes, hyperglycaemia and arterial disease. In Complications of Diabetes. 2nd edition. H. Keen and J. Jarrett, editors. Edward Arnold, London. 179-203.

2. Kennedy, L., and J. W. Baynes. 1984. Non-enzymatic glycosylation and the chronic complications of diabetes: an overview. Diabetologia. 26:93-98.

3. Crabbe, M. J. C., editor. 1987. Diabetic Complications. Churchill-Livingstone Inc., New York. 257 pp. 
4. Merimee, T. J. 1990. Diabetic retinopathy: a synthesis of perspectives. $N$ Engl. J. Med. 322:978-983.

5. Greene, D. A., S. A. Lattimer, and A. A. F. Sima. 1987. Sorbitol, phosphoinositides and sodium-potassium-ATPase in the pathogenesis of diabetic complications. N. Engl. J. Med. 316:599-606.

6. Baynes, J. W. 1991. Perspectives in diabetes: role of oxidative stress in development of complications. Diabetes. 40:405-412.

7. Lyons, T. J. 1991. Oxidized lipoproteins: a role in the pathogenesis of atherosclerosis in diabetes? Diabetic Med. 8:411-419.

8. The DCCT Research Group. 1986. The Diabetes Control and Complications Trial (DCCT). Design and methodologic considerations for the feasibility phase. Diabetes. 35:530-545.

9. Pirart, J. 1978. Diabetes mellitus and its degenerative complications: a prospective study of 4400 patients observed between 1947 and 1973. Diabetes Care. 1:168-188.

10. Klein, R., B. E. K. Klein, S. E. Moss, M. D. Davis, and D. L. DeMets. 1989. Glycosylated haemoglobin predicts the incidence and progression of diabetic retinopathy. JAMA (J. Am. Med. Assoc.). 260:2864-2871.

11. Chase, H. P., W. E. Jackson, S. L. Hoops, R. S. Cockerham, P. G. Archer, and D. O'Brien. 1989. Glucose control and the renal and retinal complications of insulin-dependent diabetes. JAMA (J. Am. Med. Assoc.). 261:115-1160.

12. McCance, D. R., D. R. Hadden, A. B. Atkinson, D. B. Archer, and L. Kennedy. 1989. Long-term glycaemic control and diabetic retinopathy. Lancet. 2:824-8

13. D'Antonio, J. A., D. Ellis, and B. H. Doft. 1989. Diabetic complications and glycemic control: the Pittsburgh prospective insulin-dependent cohort study status report after five years of IDDM. Diabetes Care. 12:694-700.

14. McCance, D. R., D. R. Hadden, A. B. Atkinson, H. Johnston, and L. Kennedy. 1992. The relationship between long-term glycaemic control and diabetic nephropathy. Q. J. Med. 297:53-61.

15. Feldt-Rasmussen, B., E. R. Mathiesen, and T. Deckert. 1986. Effect of two years strict metabolic control on progression of incipient diabetic nephropathy in insulin-dependent diabetes. Lancet. 2:1300-1304.

6. Brinchmann-Hansen, O., K. Dahl-Jorgensen, L. Sandvik, and K. F. Hans sen. 1992. Blood glucose concentrations and progression of diabetic retinopathy: the seven year results of the Oslo study. Br. Med. J. 304:19-22.

17. Strowig, S., and P. Raskin. 1992. Glycemic control and diabetic complications. Diabetes Care. 15:1126-1140.

18. Schnider, S. L., and R. R. Kohn. 1981. Effects of age and diabetes mellitus on the solubility and nonenzymatic glucosylation of human skin collagen. $J$ Clin. Invest. 67:1630-1635.

19. Yue, D. K., S. McLennan, L. Delbridge, D. J. Handelsman, T. Reeve, and J. R. Turtle. 1983. The thermal stability of collagen in diabetic rats: correlation with severity of diabetes and non-enzymatic glycation. Diabetologia. 24:282285 .

20. Kohn, R. R. 1978. Principles of Mammalian Aging. Prentice-Hall Inc., Englewood Cliffs, NJ. pp 37-44.

21. Hamlin, C. R., R. R. Kohn, and J. H. Luschin. 1975. Apparent accelerated aging of human collagen in diabetes mellitus. Diabetes. 24:902-904.

22. Dyer, D. G., J. A. Dunn, S. R. Thorpe, T. J. Lyons, D. R. McCance, and J. W. Baynes. 1993. Accumulation of Maillard reaction products in skin collagen in diabetes and aging. J. Clin. Invest. 91:2463-2469.

23. Dunn, J. A., D. R. McCance, S. R. Thorpe, T. J. Lyons, and J. W. Baynes. 1991. Age-dependent accumulation of $N^{*}$-(carboxymethyl) lysine and $N^{*}$-(carboxymethyl)hydroxylysine in human skin collagen. Biochemistry. 30:12051210.

24. Lyons, T. J., and L. Kennedy. 1985. Nonenzymatic glycosylation of skin collagen in patients with limited joint mobility. Diabetologia. 28:2-5.

25. Vishwanath, V., K. E. Frank, C. A. Elmets, P. J. Dauchot, and V. M. Monnier. 1986. Glycation of skin collagen in type I diabetes mellitus: correlation with long-term complications. Diabetes. 35:916-921.

26. Lyons, T. J., K. E. Bailie, D. G. Dyer, J. A. Dunn, and J. W. Baynes. 1991. Decrease in skin collagen glycation with improved glycemic control in patients with insulin-dependent diabetes mellitus. J. Clin. Invest. 87:1910-1915.

27. Lyons, T. J., and L. Kennedy. 1985. Effect of in vitro non-enzymatic glycosylation of human skin collagen on susceptibility to collagenase digestion. Eur. J. Clin. Invest. 15:128-131.

28. Maillard, L. C. 1912. Action des acides amines sur les sucres: formation des melaniodines par voie methodique. C. R. Acad. Sci. (Paris). 154:66-68.

29. Baynes, J. W., and V. M. Monnier, editors. 1989. The Maillard Reaction in Aging, Diabetes and Nutrition. Alan R. Liss, Inc., New York. 410 pp.

30. Finot, P. A., H. U. Aeschbacher, R. F. Hurrell, and R. Liardon, editors. 1990. The Maillard Reaction in Food Processing, Human Nutrition and Physiology. Birkhäuser Verlag, Basel. 516 pp.

31. Wolff, S. P. 1987. The potential role of oxidative stress in diabetes and its complications: novel implications for therapy and practice. In Diabetic Complications. M. J. C. Crabbe, editor. Churchill-Livingstone Inc., New York. 167-220.

32. Sell, D. R., A. Lapolla, P. Odetti, J. Fogarty, and V. M. Monnier. 1992.
Pentosidine formation in skin correlates with severity of complications in individuals with long-standing IDDM. Diabetes 41:1286-1292.

33. Monnier, V. M., D. R. Sell, F. W. Abdul-Karim, and S. N. Emancipator. 1988. Collagen browning and cross-linking are increased in chronic experimenta hyperglycemia: relevance to diabetes and aging. Diabetes. 377:868-872.

34. Kohn, R. R., A. Cerami, and V. M. Monnier. 1984. Collagen aging in vitro by non-enzymatic glycosylation and browning. Diabetes. 33:57-59.

35. Dominiczak, M. H., J. Bell, N. H. Cox, D. C. McCruden, S. K. Jones, A. Y. Finlay, I. W. Percy-Robb, and B. M. Frier. 1990. Increased collagen-linked fluorescence in skin collagen of young patients with type I diabetes mellitus. Diabetes Care. 13:468-472.

36. Monnier, V. M., R. R. Kohn, and A. Cerami. 1984. Accelerated age-related browning of human collagen in diabetes mellitus. Proc. Natl. Acad. Sci. USA. 81:583-587.

37. Fu, M-X., K. J. Knecht, S. R. Thorpe, and J. W. Baynes. 1992. Role of oxygen in cross-linking and chemical modification of collagen by glucose. Diabetes. 41 (Suppl. 2):42-48.

38. Brownlee, M., H. Vlassara, and A. Cerami. 1984. Non-enzymatic glycosylation and the pathogenesis of diabetic complications. Ann. Intern. Med. 101:527537.

39. Editorial. 1986. Browning and diabetic complications. Lancet. 1:1192193.

40. Brownlee, M., A. Cerami, and H. Vlassara. 1988. Advanced glycosylation end products in tissue and the biochemical basis of diabetic complications. $N$. Engl. J. Med. 318:1315-1321.

41. Monnier, V. M., V. Vishwanath, K. E. Frank, C. A. Elmets, P. J. Dauchot, and R. R. Kohn. 1986. Relation between complications of type I diabetes mellitus and collagen-linked fluorescence. N. Engl. J. Med. 314:403-408.

42. Oimomi, M., Y. Maeda, S. Baba, and M. Yamamato. 1989. Relationship between levels of advanced-stage products of the Maillard reaction and the development of diabetic retinopathy. Exp. Eye Res. 49:317-320.

43. Makita, Z., S. Radoff, E. J. Rayfield, Z. Yang, E. Skolnik, V. Delaney, E. A. Friedman, A. Cerami, and H. Vlassara. 1991. Advanced glycosylation end products in patients with diabetic nephropathy. $N$. Engl. J. Med. 325:836-842.

44. Fujimori, E. 1989. Cross-linking and fluorescence changes of collagen by glycation and oxidation. Biochim. Biophys. Acta. 998:105-110.

45. Ahmed, M. U., S. R. Thorpe, and J. W. Baynes. 1986. Identification of $N^{*}$-( carboxymethyl)lysine as a degradation product of fructoselysine in glycated protein. J. Biol. Chem. 261:4889-4894.

46. Ahmed, M. U., J. A. Dunn, M. D. Walla, S. R. Thorpe, and J. W. Baynes 1988. Oxidative degradation of glucose adducts to protein of 3-( $N^{*}-$ lysino $)$ lactic acid from model compounds and glycated proteins. J. Biol. Chem. 263:88168821 .

47. Dunn, J. A., J. S. Patrick, S. R. Thorpe, and J. W. Baynes. 1989. Oxidation of glycated proteins: age-dependent accumulation of $N^{*}$-(carboxymethyl) lysine in human lens protein. Biochemistry. 28:9464-9468.

48. Sell, D. R., and V. M. Monnier. 1989. Structure elucidation of a senescence cross-link from human extracellular matrix: implication of pentose in the aging process. J. Biol. Chem. 264:21597-21602.

49. Sell, D. R., and V. M. Monnier. 1990. End-stage renal disease and diabetes catalyze the formation of a pentose-derived crosslink from aging human collagen. J. Clin. Invest. 85:380-384.

50. Dunn, J. W., D. G. Dyer, K. J. Knecht, S. R. Thorpe, D. R. McCance, K Bailie, G. Silvestri, T. J. Lyons, and J. W. Baynes. 1990. Accumulation of Maillard reaction products in tissue proteins. In The Maillard Reaction in Food Processing, Human Nutrition and Physiology. P. A. Finot, H. U. Aeschbacher, R. F. Hurrell, and R. Liardon, editors. Birkhäuser Verlag, Basel. 425-430.

51. Dyer, D. G., J. A. Blackledge, S. R. Thorpe, and J. W. Baynes. 1991. Formation of pentosidine during non-enzymatic browning of proteins by glucose: identification of glucose and other carbohydrates as possible precursors of pentosidine in vivo. J. Biol. Chem. 266:11654-11660.

52. National Diabetes Data Group. 1979. Classification and diagnosis of diabetes mellitus and other categories of glucose intolerance. Diabetes. 28:10391057

53. Rosenbloom, A. L., J. H. Silverstein, D. C. Lezotte, K. Richardson, and M. McCallum. 1981. Limited joint mobility in childhood diabetes mellitus indicates increased risk for microvascular disease. N. Engl. J. Med. 305:191-194.

54. Grgic, A., A. L. Rosenbloom, F. T. Weber, B. Giordano, J. I. Malone, and J. J. Shuster. 1976. Joint contracture-a common manifestation of childhood diabetes. J. Paediatr. 88:584-588.

55. Mirsky, I. A., P. Futterman, and R. H. Broh-Kuhn. 1953. The quantitative measurement of vibration perception in subjects with and without diabetes. J. Lab. Clin. Med. 41:221-235.

56. Harrel, F. E. 1983. The logist procedure. In SAS Institute, Inc., SUGI Supplemental Library User's Guide. SAS Institute, Raleigh, NC. 181-202.

57. Jones, A. F., and J. Lunec. 1987. Protein fluorescence and its relationship to free radical activity. Br. J. Cancer. 55(Suppl. 8):6065. 
58. Oberly, L. W. 1988. Free radicals and diabetes. Free Radical Biol. Med. 5:113-124.

59. Bucala, R., K. J. Tracey, and A. Cerami. 1991. Advanced glycosylation products quench nitric oxide and mediate defective endothelium-dependent vasodilatation in experimental diabetes. J. Clin. Invest. 87:432-438.

60. Hogan, M., A. Cerami, and R. Bucala. 1992. Advanced glycosylation endproducts block the antiproliferative effect of nitric oxide: Role in the vascular and renal complications of diabetes mellitus. J. Clin. Invest. 90:1110-1115.

61. Brownlee, M., H. Vlassara, A. Kooney, P. Ulrich, and A. Cerami. 1986. Aminoguanidine prevents diabetes-induced arterial protein cross-linking. Science (Wash. DC). 232:1629-1632.

62. Hammes, H. P., S. Martin, K. Federlin, K. Geisen, and M. Brownlee. 1991. Aminoguanidine treatment inhibits the development of experimental diabetic retinopathy. Proc. Natl. Acad. Sci. USA. 88:11555-11558.

63. Soulis-Liparota, T., M. Cooper, D. Papazoglou, B. Clarke, and G. Jerums. 1991. Retardation by aminoguanidine of development of albuminuria, mesangial expansion, and tissue fluorescence in streptozotocin-induced diabetic rat. Diabetes. 40:1328-1324.
64. Yagihashi, S., M. Kamijo, M. Baba, N. Yagihashi, and K. Nagai. 1992. Effect of aminoguanidine on functional and structural abnormalities in peripheral nerve of STZ-induced diabetic rats. Diabetes. 41:47-52.

65. Lyons, T. J., S. R. Thorpe, and J. W. Baynes. 1992. Glycation and oxidation of proteins in aging and diabetes. In Glucose Metabolism, Diabetes and the Vascular Wall. N. Ruderman, M. Brownlee, and J. R. Williamson, editors. Oxford University Press, New York. 197-217.

66. Rohrbach, D. H., J. R. Hassell, H. K. Kleinman, and G. R. Martin. 1982. Alterations in basement membrane (heparin sulphate) proteoglycan in diabetic mice. Diabetes. 31:185-188.

67. Yue, D. K., B. Swanson, S. McLennan, M. Marsh, J. Spaliivero, L. Delbridge, T. Reeve, and J. R. Turtle. 1986. Abnormalities of granulation tissue and collagen formation in experimental diabetes, uraemia and malnutrition. Diabetic Med. 3:221-225.

68. Cohen, M. P., H. Klepser, and V.-Y. Wu. 1989. Undersulphation of glomerular basement membrane heparin sulphate in experimental diabetes and lack of correction with aldose reductase inhibition. Diabetes. 37:1324-1327. 